\title{
The educational problem that MOOCs could solve: professional development for teachers of disadvantaged students
}

\author{
Diana Laurillard* \\ London Knowledge Lab, UCL Institute of Education, London, United Kingdom
}

(Received 6 August 2015; final version received 31 January 2016)

\begin{abstract}
The demographics of massive open online course (MOOC) analytics show that the great majority of learners are highly qualified professionals, and not, as originally envisaged, the global community of disadvantaged learners who have no access to good higher education. MOOC pedagogy fits well with the combination of instruction and peer community learning found in most professional development. A UNESCO study therefore set out to test the efficacy of an experimental course for teachers who need but do not receive high-quality continuing professional development, as a way of exploiting what MOOCs can do indirectly to serve disadvantaged students. The course was based on case studies around the world of information and communication technology (ICT) in primary education and was carried out to contribute to the UNESCO "Education For All" goal. It used a co-learning approach to engage the primary teaching community in exploring ways of using ICT in primary education. Course analytics, forums and participant surveys demonstrated that it worked well. The paper concludes by arguing that this technology has the power to tackle the large-scale educational problem of developing the primary-level teachers needed to meet the goal of universal education.
\end{abstract}

Keywords: MOOCs; blended learning; disadvantaged students; teaching designers; peer learning; learning community; professional development

\section{Introduction}

Digital technologies can do much for education, but it is suboptimal to ask 'what problem can we solve with this technology?' This is what happened when the first free online courses from top US universities attracted massive student numbers. Big numbers attract investment, and this led to the development of learning platforms to manage teaching activities on the large scale. Then the rhetoric needed the big problems to match the invention of the massive open online course (MOOC), and "Education For All" was the obvious candidate.

Access to higher education is one of the very big problems in education. For example, by 2025 the global demand for higher education is predicted to double to $\sim 200 \mathrm{~m}$ per year, mostly from emerging economies (NAFSA 2010). The early excitement about MOOCs coalesced around the idea that they could potentially be a solution to this massive educational problem (Laurillard 2014).

\footnotetext{
*Email: d.laurillard@ioe.ac.uk

Responsible Editor: Carlo Perrotta, University of Leeds, United Kingdom.
} 


\section{Laurillard}

\section{The problems MOOCs could solve}

However, the demographics of MOOCs are not moving in that direction. By far the most popular on the Coursera platform are those in the IT and Finance areas, which update the already highly skilled professionals in those areas. The Harvard and MIT platforms, offering a wide range of subject areas, attract participants of whom $72 \%$ and $63 \%$, respectively, already have a bachelor degree or more (Ho et al. 2014). The equivalent Coursera figures are $85 \%$ (Coursera 2014). So the massive numbers are not the intended pre-undergraduate population, but highly qualified professionals. Of the Harvard-MIT participants, only $2.7 \%$ are from the UN 'least developed countries'. In the context of massive courses this is $>20,000$ people, which seems an impressive advance, except that these are not degree awarding courses, and even 20,000 is a drop in the ocean of unmet need (Daniel, 2012).

The problem that MOOCs are actually solving, therefore, is how to provide free education to highly qualified professionals - not a problem anyone had previously thought to identify.

If, instead of starting with the technology, we take a major education problem, such as Education For All, ${ }^{1}$ or raising learning outcomes in the poorest countries, ${ }^{2}$ and ask 'how can technology help?', what follows has to be an analysis of what it would take to achieve that. UNESCO estimates that universal primary education requires $\sim 1.6 \mathrm{~m}$ new teachers in the poorest countries. Similarly, the raising of learning outcomes is being tackled through research that will "provide policymakers and practitioners with concrete ideas on how to improve learning, and understanding of how these will translate to their specific contexts and institutions' (ESRC-DfID Call 2015). ${ }^{2}$ Ask how technology can help at this stage in analysing the problem, and one answer could well take the form of an MOOC.

\section{The nature of professional development for teachers}

One of the critical issues identified in many studies of continuing professional development (CPD) for teachers, especially with respect to the adoption of learning technology, is lack of time to innovate, closely followed by lack of support or leadership (Dowker 2009; Griffin 2004; Knight, Tait, and Yorke 2006). Another more general study identified an even more important factor: the lack of collaboration among educators within their department, across subject matter groups, and with educational science itself (Hökkä and Eteläpelto 2014). The authors conclude that there are two requirements for professional development that:

a. individual teacher educators can learn, renegotiate their professional identities and maintain their enthusiasm and commitment

b. teacher education communities and organisations can create innovative and collaborative ways to implement teacher education in the future (Hökkä and Eteläpelto 2014, p. 49).

This analysis matches the findings of a recent study of reports on teacher professional development programmes that have a more reflective and iterative approach. It shows that the nature of CPD for teachers is beginning to change. The traditional in-service training (INSET) approach that delivers information and guidance to teachers is shifting towards a co-learning approach. It documents the recognition that teachers' 
own knowledge and experience must be at the heart of professional development, to make it something done with them, not done to them. Co-learning involves:

networking and interchanges among schools and situations and is strengthened in formalised experiences such as courses and workshops that introduce peer coaching or support collaboration and joint projects... the lesson learned is that teachers naturally talk to each other, and that such talk can take on an educational purpose. (Avalos 2011, p. 18)

From both studies it seems evident that unless teachers are the 'prime actors' in their own development, it will be impossible for them to keep up with the rapid changes in the environment, political, cultural, economic and, especially, technological.

\section{The MOOC as co-learning for professional development}

This paper gives an account of a problem for which an MOOC offered a real solution.

Faced with the problem of how best to communicate a report on the findings of a UNESCO study on ICT in Primary Education, which documented the innovative practice of teachers across 19 different countries, the report authors decided to investigate the use of an MOOC format. The aim was to promote the use of information and communication technology (ICT) in primary education, especially in those countries where this is uncommon, or even resisted. Publishing a book is unquestionably an instructivist approach to professional development; we wanted a more collaborative and constructivist engagement with teachers. What works in one school does not necessarily work in another, so the basic principles of using learning technology must be debated and contextualised by the professionals themselves, if adoption is to succeed. This teacher-centred, co-learning approach follows exactly the ideas proposed by Avalos, and Hökkä and Eteläpelto.

The affordances of the main MOOC platforms focus on presentation formats, such as video lectures and reading resources, supported by automated testing (mostly forms of multiple choice questions), discussion forums, and peer-reviewed assignments. Clearly, the opportunities for co-learning were limited, but could an MOOC be viable, nonetheless?

In their analysis of the current evidence of institutional approaches to MOOCs, Hollands and Tirthali (2014) found that the forums in MOOCs tend to be used for question-and-answer (Q\&A), rather than peer discussion. Since peer discussion is the main opportunity for co-learning in an MOOC, this is not promising. However, Bayne and Ross, in their review of five UK MOOCs, made the important point that 'MOOC pedagogy is not embedded in MOOC platforms, but is negotiated and emergent' (Bayne and Ross 2014, p. 8), that is, the prevalence of Q\&A is not a property of the platform: the way forums are used depends on the pedagogic design. Both discussions and assignments could be used to support co-learning. MOOC pedagogy has the potential to go beyond the assumed affordances of the MOOC platform and find ways of making connections between learners and their peers, and between learners and facilitators (Kop, Fournier, and Mak 2011).

Recent reviews make the point that MOOCs for professional teacher development have been poorly researched (Jobe, Östlund, and Svensson 2014), and that the pedagogy of MOOCs has not received sufficient focus and needs greater attention (Bayne and Ross 2014). This paper is intended as a contribution to fill that gap. 


\section{Laurillard}

The aim of our project was to design an MOOC that would promote a form of colearning to provide the type of teacher professional development that researchers argue is now needed.

\section{The MOOC as professional co-learning: A case study}

This paper documents the results of an investigation into the MOOC as CPD, carried out in collaboration with the UNESCO Institute for IT in Education (IITE). The main mission of the IITE is to bridge the digital divide in education: building inclusive knowledge societies, reinforcing national capacities, promoting e-environments and increasing access to education and lifelong learning. ${ }^{3}$ In the context of the UNESCO "Education For All" programme, the value of an MOOC in particular was its potential to reach teachers in the emerging economies.

Our initial question was: to what extent could such an open online course succeed in bringing a co-learning model of professional development to large numbers of teachers, especially in the emerging economies, as a contribution to solving the educational challenge of integrating ICT effectively into primary education?

\section{Course design and development}

The course was developed on the Coursera platform, hosted by the University of London International Programmes. The course team was formed of the authors of three volumes of research studies, funded by the UNESCO Institute of IT in Education, ${ }^{4}$ to bring an understanding of ICT in primary education to a wide audience (Kalaš et al. 2012, 2014; Lim et al. 2014). The material in the three volumes were extracted for the readings, along with videos and texts provided by the 32 case studies from schools around the world.

The course team was formed by the eight researchers who had developed the three books on which it was based, with one member (the author of this paper) acting as lead instructor and chair of the team.

\section{The design process}

With eight members in different countries and time zones, there were few opportunities for face-to-face collaboration, so we used two Skype meetings to discuss and agree overall planning and scheduling, took advantage of members' international travel for occasional small group meetings and used one-one Skype meetings between the lead instructor and other members to fine tune designs.

The team used a shared Googledoc to plan the teaching-learning activities. The overall pedagogic approach was designed for the first week by the lead instructor, which provided the model for the remaining weeks. As the design for each week was completed, the technical designer transferred it to the Coursera platform, so that instructors could edit the study guide, add further resources and forum activities, and edit the assignment instructions and rubrics.

An experienced primary training educator was employed to carry out detailed developmental testing and give feedback on problems that would need redesign. The first 2 weeks of the course were submitted to a quality assurance panel at the University of London for final approval. 


\section{The intended learning outcomes for the course}

Given the overall aim to bring an understanding of ICT in primary education to a wide audience, the course was targeted at primary education leaders, teachers and policymakers in all countries, and had the following intended learning outcomes:

(1) The primary school teaching community to be able to contribute to the integration of a range of effective ICT-based practices and pedagogies.

(2) School leaders to be able to develop, improve and share the strategies and mechanisms that optimise the development of ICT-based teaching and learning in their school.

(3) Policymakers and schools-related stakeholders, agencies and companies to be able to support head teachers and specialist staff in developing pedagogy-led and problem-led uses of ICT.

(4) For all participants, a greater awareness of the range of pedagogic innovation that uses ICT, and the many free technology tools now available, to enhance primary education.

\section{Teaching and learning activities}

The standard MOOC pedagogy is to provide a mix of presentations (videos, digital resources), automated assessment, peer-assessed assignments and peer discussions Conole 2013). The format is a good fit with the pedagogy of the standard CPD course, which provides presentations to update participants on the latest research and developments, along with peer discussion and a non-assessed certificate of attendance. CPD requirements make it possible to run MOOCs on a very large scale, as they require only the fixed teaching costs of preparation, and none of the variable teaching costs of student support while the course is running.

Like other MOOC platforms, Coursera does not easily support the kind of collaborative learning we intended. In addition to the presentations and discussions, we wanted participants to be able to work in peer groups, sharing experiences, ideas and expertise. This is in line with the co-learning approach to CPD that recognises the great value of the experience and expertise that teachers can offer each other.

The pedagogy of this CPD MOOC combined curated digital resources with orchestrated peer collaboration. Curating the resources of videos, texts, case studies and research findings is straightforward on an MOOC platform. Collaboration is more difficult and typically has to be done off-platform. 'Orchestrating' collaboration is essential. The process has to be carefully designed; it does not just happen by providing forums.

To enable participants to share ideas and experiences, they were invited to provide links to 'show-and-tell' case studies of their ICT-based pedagogies, and examples of technology tools and resources they used in their teaching. We did this by setting up external sites such as Padlet and Diigo, where they could share and comment on each other's contributions. It was important then to bring them back to the course on the MOOC platform, so we set up discussion forums that did not rely on participants to organise their own knowledge-building (de Waard 2015) but guided them to focus on explicit issues relating to their contributions on each of the external sites.

Through these activities, participants were able to make contacts and create professional connections, and learn about and discover technologies for their own use, building on each other's contributions. 


\section{Laurillard}

\section{A study guide for activities}

The typical MOOC format for a week of study begins with an overview (in the Announcement) and access to the video lectures, quizzes, forums and other resources, with guidance on how to use each one. Instead of this, given our strong focus on contextualised practice and collaborative learning, the team designed each week as a clear study guide in the form of a sequence of resources and activities linked by tutorial text (see Figure 1). The main distinctive pedagogic features were:

(1) Indication of activities that were core for passing the course, or optional

(2) Expected learning time for each activity

(3) External resources and tools to support course resources

(4) Guidance on how to learn from each activity

(5) Issue-focused forums to focus discussion

(6) Links to external sites for sharing experiences, ideas and resources

(7) Advice on building a Course Journal for use after the course.

The first four features were designed to support the participants in independent but guided learning; the next two were to support co-learning using the external sites to support participants in learning from each other; and the Course Journal was to ensure they would be able to take something of use from the course into their normal teaching.

\section{Supporting collaborative learning}

Collaborative learning goes beyond discussion learning by bringing 'constructionism' (Kolb 1984; Papert 1980) to combine with the social learning of 'social constructivism'

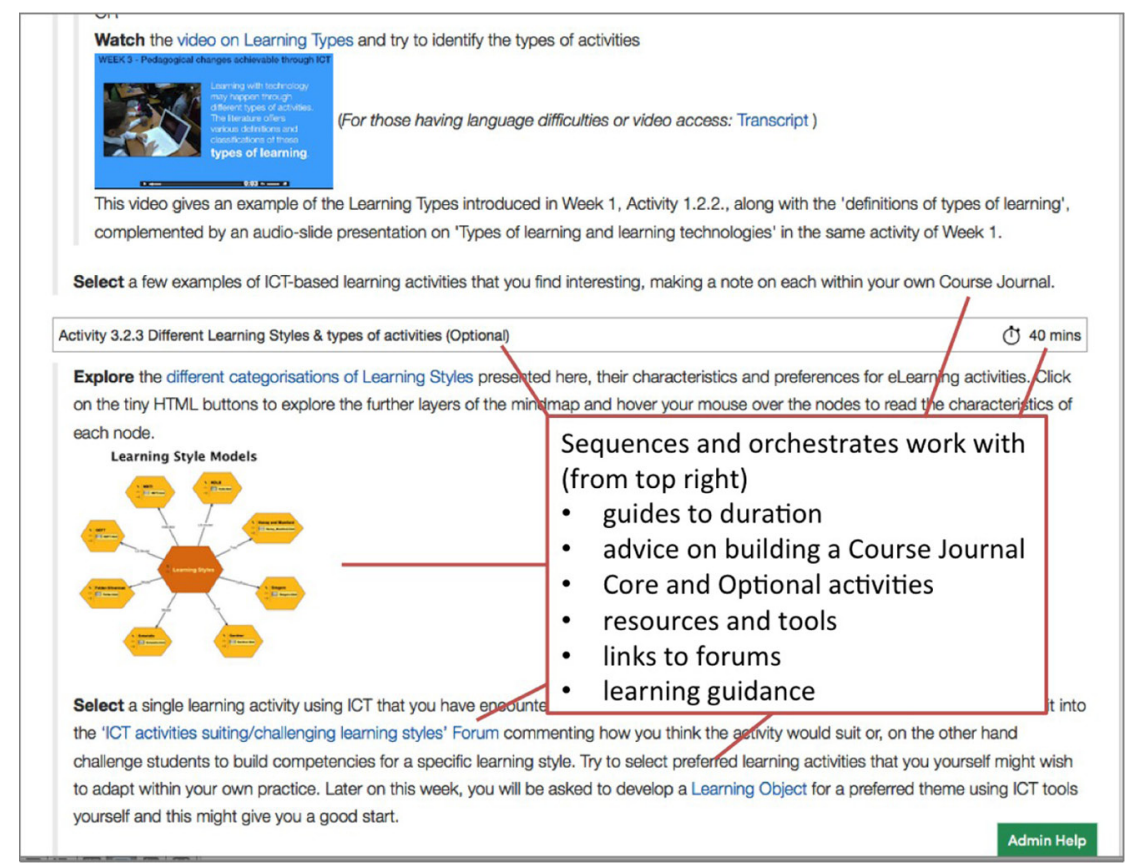

Figure 1. Showing some of the key features of the pedagogic style. 
(Vygotsky 1978; Wertsch 1985), and thereby adds to discussion learning the requirement to produce a joint construction. This could be as simple as a definition or summary, and as complex as a design or a research finding. Without the joint output, discussion can be relatively unchallenging and unresolved, whereas in order to produce a joint output it is essential for students to debate and negotiate until the single shared product can be delivered. This is a much richer learning experience because it gives focus to the discussion and enables students to learn from and build on the outputs of their peers and to share their reflections and interpretations of what happened within their practice (Laurillard 2009). It also needs more guidance than is typical for MOOCs, in which participants are often encouraged to use social media to develop their own knowledge-building communities, without any guidance (de Waard 2015; Liyanagunawardena, Adams, and Williams 2013).

For teachers learning from each other about the optimal use of technology, the shared output could be, for example, a comparison between different technologies to use for a particular learning outcome, or an analysis of student performance under different conditions, or a learning design to improve the impact of a technology. However, this would mean being able not just to discuss and debate online but also to create and share their practice outputs as well. MOOC platforms do not easily support this. Table 1 sets out the requirements for truly collaborative learning (Laurillard 2012), the ways in which digital technology could support them, and the extent to which MOOCs succeed in doing so.

It is clear, therefore, that although it is possible to extend the community learning capability of MOOCs by linking to external sites and off-platform collaboration tools, MOOCs tend to support only discussion learning, not the more challenging and richer form of collaborative learning that includes the joint construction of a shared output.

\section{Assessment}

In line with standard CPD design, there was no formal assessment of the ICT in Primary Education course. The automated assessment methods using quizzes were not appropriate for evaluating the qualitative descriptions and localised interpretations of theory that were the main outputs from participants. Peer assessment was the only form of assessment used.

Studies of peer assessment methods used in MOOCs have emphasised the importance of using qualitative assessment which recipients can use as guidance for improving their work (Carless et al. 2010), and of guiding their assessment by defining criteria and scoring rubrics to improve the validity (Luo, Robinson, and Park 2014). For our teacher participants, the assignments asked them to develop documents, plans or resources for their future work beyond the course. Each assignment had a set of criteria, which participants could use to assess their peers, giving scores and constructive qualitative feedback.

The four peer-assessed assignments were to:

- Create and describe a learning object

- Develop a 'technology decision' for their school or class

- Prepare a suggestion for tackling one of the key challenges identified in the literature

- Design a two-page brochure or newsletter to inform policymakers about the issues of implementation 


\section{Laurillard}

Table 1. The extent to which digital technologies, in general, and MOOC platforms, in particular, support the optimal conditions for collaborative learning.

\begin{tabular}{|c|c|c|}
\hline Requirements & What technology could offer & $\begin{array}{l}\text { What MOOC platforms offer } \\
\text { Italics indicate 'off-platform' }\end{array}$ \\
\hline 1. A shared task goal & $\begin{array}{l}\text { This is for the teacher to } \\
\text { specify }\end{array}$ & $\begin{array}{l}\text { Instructions for the learning } \\
\text { task }\end{array}$ \\
\hline $\begin{array}{l}\text { 2. Resources relevant to } \\
\text { the task }\end{array}$ & $\begin{array}{l}\text { Websites, digital libraries, } \\
\text { OERs, collaboration tools }\end{array}$ & $\begin{array}{l}\text { Course videos and texts } \\
\text { Links to external resources } \\
\text { and tools }\end{array}$ \\
\hline $\begin{array}{l}\text { 3. The means to discuss } \\
\text { the task }\end{array}$ & $\begin{array}{l}\text { Online discussion } \\
\text { environment, synchronous } \\
\text { and asynchronous, recording } \\
\text { all discussions }\end{array}$ & $\begin{array}{l}\text { Open asynchronous forums } \\
\text { Links to external tools for } \\
\text { recording webinars or } \\
\text { hangouts }\end{array}$ \\
\hline $\begin{array}{l}\text { 4. Guidance on managing } \\
\text { the discussion-solution } \\
\text { process }\end{array}$ & $\begin{array}{l}\text { Study guide, roles, scripts, } \\
\text { worksheets, teacher } \\
\text { intervention }\end{array}$ & $\begin{array}{l}\text { Orchestration of the learning } \\
\text { task in the study guide }\end{array}$ \\
\hline $\begin{array}{l}\text { 5. The means to construct } \\
\text { and revise representations } \\
\text { of meeting the task goal }\end{array}$ & $\begin{array}{l}\text { Applications for creating } \\
\text { visual representations, user- } \\
\text { generated content }\end{array}$ & $\begin{array}{l}\text { Links to external tools for } \\
\text { user-generated content, } \\
\text { designs, representations }\end{array}$ \\
\hline $\begin{array}{l}\text { 6. The means to share } \\
\text { representations of meeting } \\
\text { the task goal }\end{array}$ & $\begin{array}{l}\text { Design environment, file } \\
\text { exchange, file management }\end{array}$ & $\begin{array}{l}\text { Links to external tools for } \\
\text { exchanging user-generated } \\
\text { content }\end{array}$ \\
\hline $\begin{array}{l}\text { 7. The means to test ideas } \\
\text { and solutions for meeting } \\
\text { the task goal }\end{array}$ & $\begin{array}{l}\text { A modelling environment } \\
\text { that gives intrinsic feedback } \\
\text { on the learner's solution }\end{array}$ & $\begin{array}{l}\text { Links to external modelling } \\
\text { environments for testing ideas }\end{array}$ \\
\hline
\end{tabular}

In each case they could use within their assignment what they had produced during prior activities on the course. The requirement to review the outputs of their peers was also an opportunity for participants to use this experience to improve on their own outputs.

\section{Summary of the course design approach}

In summary the pedagogic principles governing the design of the course were:

- To curate the most useful evidence and resources for teachers, heads and policymakers

- To orchestrate the teaching community's co-learning that would build their knowledge of using digital technology

- To guide participants' study planning by providing core and optional activities, and recommended timings for each one

- To engage participants in making best use of learning technologies through guided activities, issue-focused discussions and both independent and collaborative learning

- To provide the tools and activities that enable participants to build their learning on the course into their working practices

The most difficult design challenge was to meet the full requirements of collaborative learning as outlined in Table 1. Collaboration is only viable for small groups, and on Coursera it is not yet possible to group the students registered on an MOOC. The Coursera platform can orchestrate the inter-student activities involved in peer assessment, that is, the successive stages of: 
checking a student has submitted an assignment, allocating it for review by other students who have already submitted, recording and calculating scores, and advising each student of their score.

This is a valuable reciprocal learning activity, but it is not collaboration.

\section{The MOOC as community learning: an evaluation}

Our empirical study evaluated an instantiation of professional community learning in a particular course to answer the general question:

to what extent could an open online course succeed in bringing a co-learning model of professional development to large numbers of teachers, especially in the emerging economies, as a contribution to solving the educational challenge of integrating ICT effectively into primary education?

This course focused on learning technology, which must play an important part in supporting primary education if only because of its potential to support independent adaptive learning for many topics in the primary curriculum (Kalaš et al. 2014; Butterworth and Laurillard, 2010; Robertson and Howells, 2008; Smeets 2005). This was a basic and unquestioned premise of the course, so the research questions we had to answer are:

- Can it reach large numbers of teachers in the emerging economies?

- Can an MOOC support meaningful professional development?

- Can one course be of value to such a diverse group of teachers, in terms of the practical impact in their local educational context?

We might succeed in the first two by the simple expedient of placing a course on an MOOC platform, so the third point is the real challenge.

The data reported here is collected either by the extensive analytics provided by Coursera, or from the pre- and post-course surveys run by the course team.

\section{Reaching teachers in the emerging economies}

The course was clearly advertised as CPD for teachers and education professionals, and indeed this was the audience it reached.

Over the duration of the course $>9000$ teachers registered, from 174 countries. The average registration on a Coursera course is $\sim 11,000$, so for our very niche topic this was a reasonable number. At the start of the course 5891 had registered, of whom $3230(54 \%)$ were active in the first week, also fairly typical.

The pre-course survey had 1150 respondents, that is, $36 \%$ of active participants, which is relatively high for such surveys. The demographic data it produced showed that the course reached its intended audience of teachers and policymakers in primary education, as well as academics from further and higher education (see Figure 2).

The educational level of the participants was high at $89 \%$ with degrees, as would be expected of a CPD course, but this was not much higher than the Coursera average of $\sim 80 \%$ for general courses. 


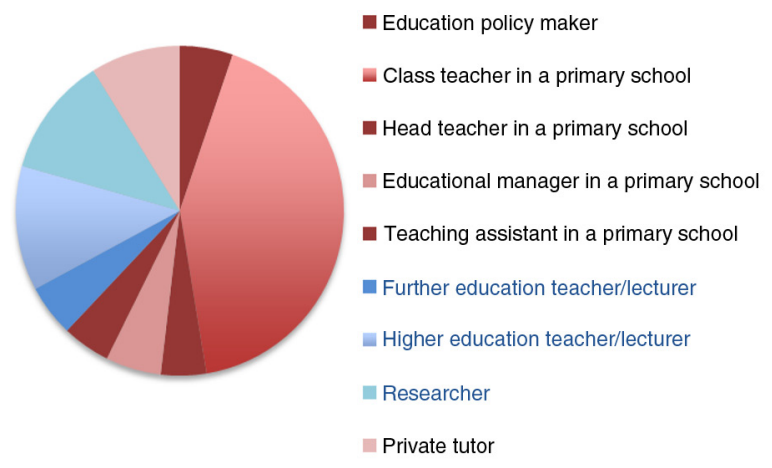

Figure 2. Showing that the course attracted the intended audience.

More interesting for our first research question was the reach to emerging economies. Participation reached 174 countries, and the registration percentage from Africa and Oceania was 7\% and 4\%, respectively, almost double that of the Coursera averages of $4 \%$ and $2 \%$, respectively. We also looked at participation from the emerging economies by investigating the 60 'countries of focus' identified by DfID 5 as those with the most challenging educational problems. Coursera collects data on participation from 47 of these countries: 20 registered no participation in our course; 27 registered a total of 1282 participants, $14 \%$ of the total registration. On the one hand, there is a very long way to go to reach all countries in greatest need; on the other hand, to have reached nearly 1300 participants from 27 of them at the first attempt is remarkable, and it encourages us to think that it is viable to use MOOCs as a means of reaching some of these countries in focus. Completion rates for the 'countries of focus' were less good than for the others: $19 \%$ against the $28 \%$ average for this course.

Interestingly, the completion rates were highest for the higher status employment groups of policymakers, school managers and lecturers at 50\%, 40\% and $48 \%$, respectively, whereas class teachers were at $20 \%$. Completion may also be determined by working time spent online, as even head teachers achieved $27 \%$ completion.

\section{The value of the course as professional development}

The measures of the success of the course come from the post-course survey, which was sent to all registered participants, and elicited 174 responses $(21 \%$ of Week 6 active users). The results for the overall experience and the perceived improvement in subject understanding are shown in Figure 3.

The course received the resounding appreciation of the respondents, with a pleasing $99 \%$ rating of excellent, very good or good. Figure $3 \mathrm{~b}$ shows one reason for this: the significant improvement in participants' understanding of ICT in primary education.

It seems to have broadly achieved the intended learning outcomes in terms of satisfying participants' own expectations, as Figure 4 shows.

The agree/strongly agree scores total more than $90 \%$ on every statement and also reveal a strong appetite for a follow-on course.

There is good evidence therefore that the course was highly valued and achieved its main objectives. 
(a)

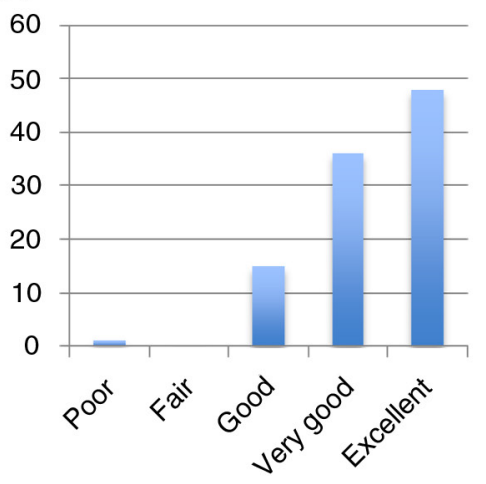

(b)

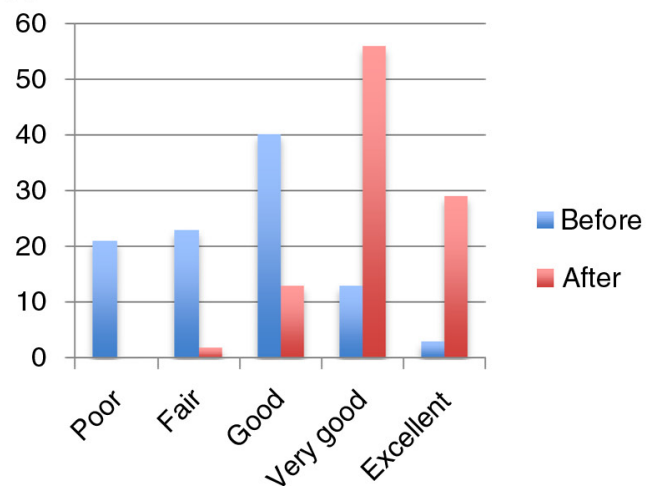

Figure 3. (a) Overall experience, and (b) change in subject understanding.

\section{Supporting community learning}

Evidence of its success as a form of community learning comes from the post-course survey, the course analytics and the content of forum posts.

Engagement in the discussion forums is an important measure of how participants value this form of peer community learning. Low participation rates in forums are a common feature of MOOCs, partly because posts are diverse comments, rather than conversations, which are difficult to manage for the very large numbers present in MOOCs. Our pedagogic design sought to overcome this by creating issue-focused forums that reduced the wide variation in points raised, and elicited more conversational discussions.

The evidence shows that engagement in the ICT in Primary Education forums was much higher than for the average MOOC, and was maintained throughout the course. Figure 5 shows this in comparison with the first four MOOCs run by the University of London, all of which reported successful results: of participants active in Week 6 around $60 \%$ watched a video, whereas only $2-3 \%$ posted in forums. By contrast, $39 \%$ of our course participants still active in Week 6 were posting in forums.

The posts to some of the later discussion forums show that teachers enjoy the issue-focused discussion forums because they value highly the experience and contributions of their peers:

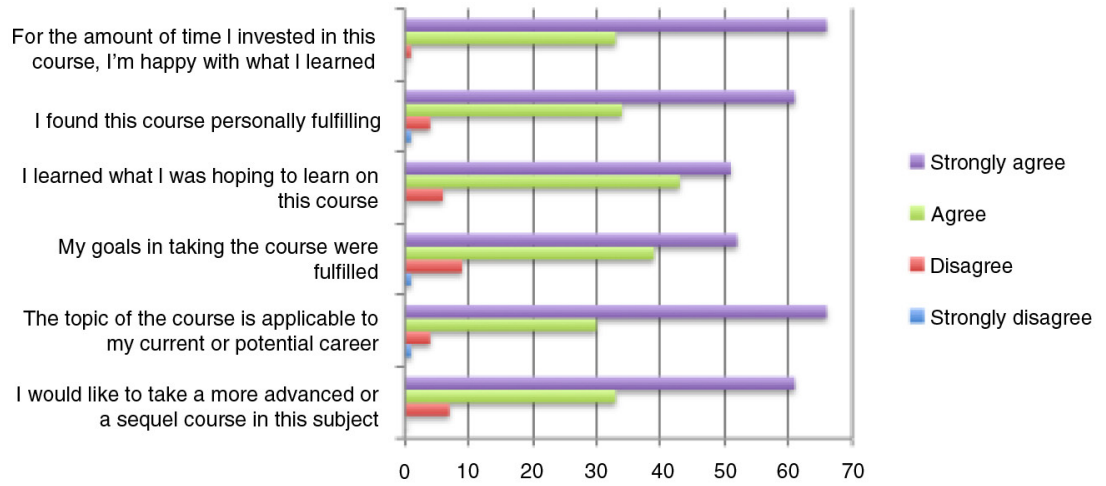

Figure 4. Participants were asked to rate their agreement or not with the above statements. 


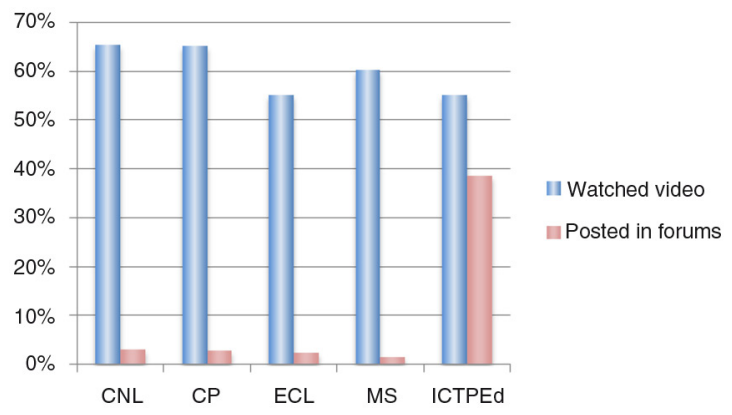

Figure 5. Of those still active in Week 6, video access was similar, but the ICT in Primary Education MOOC showed a significant difference in the forum activity.

Thanks to whole team of this course and peers. It was an interesting journey, learned and shared so much.

A Community in Practice, I really enjoyed participating.

The peer assessments for the assignments were very interesting, allowing me to learn from the practice of others in education and to see the different priorities from around the world.

We all have a common goal and that is to make a positive influence on the lives we inspire. Thanks for a great time of learning and sharing.

I have had an amazing time learning so Much from all the teachers around the world!!!

Comparing the popularity of forums, those embedded in optional activities, which had an average of 275 posts, were less popular than the forums in core activities, which had an average of 345 posts. Making an activity optional therefore risked a $20 \%$ drop in engagement.

In addition to the issue-focused discussions set up by the course team, there were also discussions relating to participants' outputs, such as lesson plans, or case studies. These were not, strictly, collaborative activities, because the platform does not lend itself easily to collaboration. We could not ask participants to work together to produce an agreed joint output as it is not possible to set up small groupings of students. The forum activity is highly appropriate for discussing issues and interpretations among peer professionals, but there is no form of shared user-generated production environment in the platform, even something as simple as a Googledoc. The closest we could get to this was to use external peer resource exchange environments such as Diigo and Scoop-It, or external Googledocs and similar tools, and link these to a forum.

It remains difficult in this platform environment to engage participants fully in collaborative learning activities that enable them to negotiate a joint output.

This is not because they are unwilling to share with each other. There are over 400 shared digital resources now sourced from these participants on the Diigo site set up for the course, creating a valuable repository of tagged and recommended resources from the peer community.

We also saw evidence of a willingness to share designs in the responses to the Learning Designer tool. ${ }^{6}$ In the forum discussing their initial use of the tool, participants often commented on the value of being able to share their learning designs:

I love the fact that we can share, co-create and better our practice in an organised and efficient way. I am going to recommend this to my student teachers especially. 
I have found it to be a fantastic tool. It helps teachers to share good knowledge and practice in teaching ICT.

The Learning Designer tools [sic] enables teachers to share their good teaching ideas which is fantastic!

... what a wonderful - simple but effective teacher tool! I love the idea of how it is all shared and adapted to suit each different context!

It is a great tool for teachers to share. I plan to use it this summer and share this site with colleagues when I return to school in the Fall.

Such comments are encouraging for the prospect of using MOOCs to promote the building of community knowledge among teachers about the optimal use of learning technology.

For a professional development course to be truly effective, teachers must be able to use their new learning in their local practice. The return to normal practice can too easily seem unmanageably distant from the inspirational course. By providing issue-focused forums that related the course resources to their normal practice, and with the reminders of the Course Journal, we hoped that teachers would end the course with a sense of empowerment to innovate. There was evidence that their enthusiasm for innovation would continue beyond the 6-week course in many of the final forum comments:

I can't express enough, how much I've gained from this course... I can't wait to go back and share all this with my co-workers. I was asked to do a presentation of my learning for my colleagues.

Our school is on the verge of 'stepping it up a notch', thanks to things learnt through this course. Merci beaucoup.

Through this course I've been able to order my thoughts and find some resources to take my school to the next level with ICT integration. There is so much to do, and I'm finding that I am the person to do it in my context.

I have learnt sooo much and have even been able to use this new knowledge to give advise to my colleagues and guide the school into a more ICT focused environment! I am truly grateful for this time to gain knowledge and experience of information technology. I will surely use these ideas with my class and share with my colleagues.

All registered participants continue to have access to the resources and activities after the formal end of the course. Indeed, a year after its end it is still being used.

There is evidence from this experience, therefore, that although it does not support fully collaborative learning, the MOOC format fits well with the objective of supporting effective co-learning for professionals, who appreciate this form of highquality learning, value each other's experience and knowledge and are willing to share their experiences to learn together. This is not the by-product of providing video lectures and open discussion forums for general education. The distinctive pedagogic design features of this course, listed above in the section 'A study guide', were explicitly intended to support a relatively homogeneous group of professionals in guided colearning, and they seem to have succeeded.

\section{Concluding discussion}

If the MOOC format is to be an effective mechanism for promoting educational innovation it must be able to support a co-learning model of professional development for the community of teachers.

This paper has demonstrated that by utilising the current functionality of MOOCs, it is possible to provide some of the critical features of a co-learning approach: 


\section{Laurillard}

- Issue-focused discussion forums that elicit valuable community discussions

- Peer-assessed assignments that enable teachers to learn from each other

- Discussion forums linked to off-platform tools for sharing resources and ideas

Collaborative learning in the form of small groups negotiating to develop a shared output is not supported within the current functionality of MOOCs, but participants still gained value from discussion of the key issues and from sharing ideas and resources in the off-platform locations, which seemed to motivate innovation and provide a sense of community exploration and shared endeavour.

Being able to collaborate on constructing a shared output is an important area for future MOOC pedagogy development because of the high value of collaborative learning for all types of student, and as a 'necessary foundation' for individual learning (Ludvigsen et al. 2015, p. 2). The functionality needed is to be able to:

- Form small groups to work together online synchronously and asynchronously

- Share a collaborative space for constructing a shared output, similar to a Googledoc

- Link asynchronous text comments to specific parts of the output to iterate improvements

- Link the output to a forum conversation, including synchronous audio and chat, for negotiating a final version of the output

These activities include learning through practice (construction and responding to feedback), discussion (comments and conversation) and production (negotiating an output for evaluation by others), making it a complex and valuable learning process.

The rapid development of other digital tools and resources useful for education will certainly continue, but the few that are designed explicitly for education rarely test their effectiveness properly with target students. The responsibility for the quality of technology-based learning therefore rests entirely with teachers - both to discover the innovations that have educational potential and to develop the best ways of using them. They deserve some specialised tools for collaboration.

The paper began by asking whether an open online course could succeed in bringing a co-learning model of professional development to large numbers of teachers in emerging economies. We have demonstrated that the free and open MOOC platform can reach thousands of teachers, even those at primary level and even those in emerging economies. The significant improvement in participants' understanding of ICT in primary education establishes the course as a clear contribution to solving the educational challenge of integrating ICT effectively into primary education

The co-learning model is important because:

a. This is now a growing trend in the professional development of teachers.

b. It is an effective way of enabling the teaching community to collaborate on keeping abreast of the potential of new learning technologies.

c. It enables them to build community pedagogic knowledge of how best to use technology.

Returning to the greatest educational challenge, could MOOCs make a contribution to achieving universal primary education? The recent UNESCO "Education For All" report (UNESCO 2014) points out that: 
Education quality is undermined by the need for additional teachers, with 1.6 million required to achieve universal primary education by 2015 and 5.1 million to achieve universal lower secondary education by 2030. (p. 186)

There is enough evidence from this carefully designed CPD MOOC to see that there is genuine potential for this technology to engage adults in the emerging economies in a form of professional development that would be commensurate with the immense challenge of capacity building on this scale for the teaching profession across the range of skills they need. Adults needing training as teachers are a different group from the professionals we were engaging with, but in many of the most challenging communities in the emerging economies there are informal and unofficial private schools being developed to fill the gaps left by the public service (Oketch et al. 2010). If the teachers on an MOOC could be given the support they need to run local training for these community leaders, not necessarily involving technology at the local level, then we can begin to see how online courses with 10,000 participants could match the scale of the $1.6 \mathrm{~m}$ teachers needed for universal primary education.

If we were to address this major educational problem and ask the question 'how can technology help?' then MOOC technology could be a solution. It is not yet good enough to provide education directly to disadvantaged students, but, as we have shown, we should now be exploiting it to develop the teachers who can.

\section{Acknowledgements}

The books that formed the basis of the course were funded by the UNESCO Institute of IT in Education. The course development was funded by the University of London International Programme and the Institute of Education.

The members of the course team were: Author, Professor Ivan Kalaš, Comenius University, Slovak Republic; Dr Ernesto Laval, Visiting Research Associate, UCL, and TIDE S.A., Chile; Professor Cher Ping Lim, The Hong Kong Institute of Education; Professor Florian Meyer, Université de Sherbrooke, Canada; Lynn Roberts, UCL Institute of Education, UK; Professor Alain Senteni Hamdan Bin Mohammed Smart University, UAE; Natalia Tokareva, UNESCO Institute for IT in Education (IITE), Russian Federation; Professor Márta Turcsányi-Szabó, Eötvös Loránd University, Hungary.

\section{Notes}

1. http://www.unesco.org/new/en/education/themes/leading-the-international-agenda/education-for-all/the-efa-movement/

2. http://www.esrc.ac.uk/funding-and-guidance/funding-opportunities/33605/esrc-dfid-raising-learning-outcomes-in-education-systems-call-2015-\%2814-may\%29.aspx

3. http://iite.unesco.org/

4. http://iite.unesco.org/

5. Department for International Development, UK Government.

6. http://learningdesigner.org - an open online tool for creating and sharing learning designs.

\section{References}

Avalos, B. (2011) 'Teacher professional development in Teaching and Teacher Education over ten years', Teaching and Teacher Education, vol. 27, pp. 10-20.

Bayne, S. \& Ross, J. (2014) The Pedagogy of the Massive Open Online Course: The UK View, Higher Education Academy, York.

Butterworth, B. \& Laurillard, D. (2010) Low numeracy and dyscalculia: identification and intervention, ZDM Mathematics Education, Special Issue on Cognitive Neuroscience and 


\section{Laurillard}

Mathematics Learning, vol. 42, no. 6, pp. 527-539. doi: http://dx.doi.org/10.1007/s11858010-0267-4

Carless, D., et al., (2010) 'Developing sustainable feedback practices', Studies in Higher Education, vol. 36, no. 4, pp. 395-407.

Conole, G. (2013) MOOCs as disruptive technologies: strategies for enhancing the learner experience and quality of MOOCs, Revista de Educación a Distancia, vol. 39, [online] Available at: http://www.um.es/ead/red/39/

Coursera. (2014) 'Coursera conference data', Paper presented at the Coursera Partners' Conference, University of London, London, UK. pp. 1-3.

Daniel, J. S. (2012) 'MOOCs: making sense of musings in a maze of myth, paradox and possibility', Journal of Interactive Media in Education, [online] Available at: http://jime. open.ac.uk/2012/18

de Waard, I. (2015) 'MOOC factors influencing teachers in formal education', Revista Mexicana de Bachillerato a Distancia', vol. 7, no. 13, pp. 1-8.

Dowker, A. D. (2009) What Works for Children with Mathematical Difficulties? The Effectiveness of Intervention Schemes (Vol. 00086-2009BKT-EN), Department for Children, Schools and Families. DCSF Publications, Nottingham, UK.

Griffin, S. (2004) 'Building number sense with Number Worlds: a mathematics program for young children', Early Childhood Research Quarterly, vol. 19, no. 2, pp. 173-180.

Ho, A. D., et al., (2014) HarvardX and MITx: The First Year of Open Online Courses HarvardX and MITx Working Paper No. 1, MIT Office of Digital Learning, Boston, USA.

Hökkä, P. \& Eteläpelto, A. (2014) 'Seeking new perspectives on the development of teacher education: a study of the Finnish context', Journal of Teacher Education, vol. 65, no. 1, pp. $39-52$.

Hollands, F. \& Tirthali, D. (2014) MOOCs: Expectations and Reality, Teachers College, Columbia University, New York.

Jobe, W., Östlund, C. \& Svensson, L. (2014) 'MOOCs for professional teacher development', in Proceedings of Society for Information Technology \& Teacher Education International Conference 2014, eds M. Searson \& M. Ochoa, AACE, Chesapeake, VA. pp. 1580-1586.

Kop, R., Fournier, H. \& Mak, J. (2011) 'A pedagogy of abundance or a pedagogy to support human beings? Participant support on massive open online courses', International Review of Research in Open and Distance Learning, vol. 12, no. 7, pp. 74-93.

Kalaš, I., et al., (eds) (2012) ICT in Primary Education. Analytical Study. Volume 1: Exploring the Origins, Settings and Initiatives, UNESCO Institute for Information Technology in Education, Moscow, Russian Federation.

Kalaš, I. et al., (2014) ICT in Primary Education: Volume 2 Policy, Practices, and Recommendations, UNESCO Institute for Information Technologies in Education, Moscow, Russian Federation.

Knight, P., Tait, J. \& Yorke, M. (2006) 'The professional learning of teachers in higher education', Studies in Higher Education, vol. 31, no. 3, pp. 319-339.

Kolb, D. A. (1984) Experiential Learning: Experience as the Source of Learning and Development, Prentice-Hall, Englewood Cliffs, NJ.

Laurillard, D. (2009) 'The pedagogical challenges to collaborative technologies', International Journal of Computer-Supported Collaborative Learning, vol. 4, no. 1, pp. 5-20.

Laurillard, D. (2012) Teaching as a Design Science: Building Pedagogical Patterns for Learning and Technology, Routledge, New York.

Laurillard, D. (2014) 'Hits and Myths: MOOCs may be a wonderful idea, but they're not viable', Times Higher Education, 16 Jan. p. 28.

Lim, C. P. et al., (2014) ICT in Primary Education. Analytical Survey Volume 3: Collective Case Study of Promising Practices, UNESCO Institute for Information Technologies in Education, Moscow, Russian Federation.

Liyanagunawardena, T., Adams, A. \& Williams, S. (2013) 'MOOCs: a systematic study of the published literature 2008-2012', The International Review of Research in Open and Distance Learning, vol. 14, no. 3, pp. 203-227.

Ludvigsen, S., et al., (2015) 'Collaboration and the formation of new knowledge artifacts', International Journal of Computer-Supported Collaborative Learning, vol. 10, no. 1, pp. 1-6.

Luo, H., Robinson, A. C. \& Park, J. Y. (2014) 'Peer grading in a MOOC: reliability, validity, and perceived effects', Journal of Asynchronous Learning Network, vol. 18, no. 2, pp. 1-14. 
NAFSA. (2010) The Changing Landscape of Global Higher Education, Association of International Educators, Washington, DC.

Oketch, M., et al., (2010) 'Why are there proportionately more poor pupils enrolled in nonstate schools in urban Kenya in spite of FPE policy? International Journal of Educational Development, vol. 30, pp. 23-32.

Papert, S. (1980) Mindstorms: Children, Computers, and Powerful Ideas, The Harvester Press, Brighton.

Robertson, J. \& Howells, C. (2008) 'Computer game design: opportunities for successful learning', Computers \& Education vol. 50, pp. 559-578.

Smeets, E. (2005) 'Does ICT contribute to powerful learning environments in primary education? Computers \& Education, vol. 44, pp. 343-355.

UNESCO. (2014) EFA Global Monitoring Report: Teaching and Learning - Achieving Quality for all EFA Global Monitoring Reports, UNESCO, Paris, France.

Vygotsky, L. S. (1978) Mind in Society: The Development of Higher Psychological Processes, Harvard University Press, Cambridge, MA.

Wertsch, J. V. (1985) Cultural, Communication, and Cognition: Vygotskian Perspectives, Cambridge University Press, Cambridge. 